Article

\title{
Study on the Catalytic Pyrolysis Mechanism of Lignite by Using Extracts as Model Compounds
}

\author{
Jianwei Liu, Qian Zhang, Litong Liang and Wei Huang * \\ Key Laboratory of Coal Science and Technology of Ministry of Education and Shanxi Province, Taiyuan \\ University of Technology, Taiyuan 030024, China; liujianwei686868@163.com (J.L.); \\ zhangqian01@tyut.edu.cn (Q.Z.); lianglitong@tyut.edu.cn (L.L.) \\ * Correspondence: huangwei@tyut.edu.cn; Tel.: +86-0351-6018-073
}

Received: 2 October 2019; Accepted: 12 November 2019; Published: 14 November 2019

\begin{abstract}
Understanding the catalytic pyrolysis mechanism of lignite is of great significance for obtaining a high yield of the target products or designing high-efficiency catalysts, which are generally derived by using simple model compounds, while the ordinary model compounds cannot represent the real atmosphere of lignite pyrolysis owing to the simple structures and single reactions. Based on the coal two-phase model, the extractable compounds are the important compositions of coal, which can reflect the partial characteristics of raw coal while obtaining a high extraction yield. Hence, a better understanding of the interaction between the coal structure and catalyst can be inferred by using a mobile phase in coal as model compounds instead of conventional simple compounds. In this work, tetrahydrofuran extracts of lignite were chosen as model compounds to study the catalytic pyrolysis mechanism with separate addition of $\mathrm{Fe}\left(\mathrm{NO}_{3}\right)_{3}$ and $\mathrm{FeCl}_{3}$ by using a thermogravimetric combined with mass spectrometry. It was found that about $77.88 \%$ of the extracts were vaporized before $700{ }^{\circ} \mathrm{C}$, and the residual yield was $22.12 \%$. With the separate addition of $5 \mathrm{wt} \%$ of $\mathrm{Fe}\left(\mathrm{NO}_{3}\right)_{3}$ and $\mathrm{FeCl}_{3}$, the conversion of the extracts increased to $84.38 \%$ and $89.66 \%$. Meanwhile, the final temperature decreased to 650 and $550{ }^{\circ} \mathrm{C}$, respectively. The addition of $\mathrm{Fe}\left(\mathrm{NO}_{3}\right)_{3}$ and $\mathrm{FeCl}_{3}$ promoted the breakage of aliphatic chains at approximately $150{ }^{\circ} \mathrm{C}$, leading to the generation of $\mathrm{CH}_{4}$ and $\mathrm{H}_{2}$ in the temperature range $100-200^{\circ} \mathrm{C}$, which were nearly invisible for that without catalyst. The addition of iron-based catalysts allowed more $\mathrm{CO}_{2}$ formation at approximately $200{ }^{\circ} \mathrm{C}$ since they enabled efficient promotion of the cleavage of carboxyl functionals at lower temperatures. The enlarged peak of $\mathrm{H}_{2} \mathrm{O}$ and $\mathrm{CH}_{4}$ at approximately $500{ }^{\circ} \mathrm{C}$ means that iron-based catalysts are significant for the cleavage of methoxy groups in the catalytic respect. Aromatic side chains facilitated cracking at approximately $500{ }^{\circ} \mathrm{C}$, leading to more light aliphatics and aromatics generation in this temperature range.
\end{abstract}

Keywords: THF extracts; iron-based catalyst; lignite

\section{Introduction}

According to BP Statistical Review of World Energy (2018), more than 30\% of the world's reserves of coals is lignite, which will be an important energy resource in this century [1]. Pyrolysis, as the initial step in nearly all coal conversion process, is considered to be the most promising way for clean and efficient utilization of lignite to get useful chemicals [2].

The addition of catalyst in the pyrolysis of lignite is a hopeful method to increase the yield of coal tar or improve the yield of desired low volatility products [3]. Theoretically, it is feasible to assist the breakage of particular chemical bonds, leading to a change in the reaction pathways, and obtaining a high selectivity for specific compounds with high values in the product stream [4-6]. Backed by the price advantage, marked availability, and environmental friendliness, Fe-based catalysts have been frequently adopted in diverse coal catalytic thermal conversions. Kang et al. [7] compared the catalytic 
hydroliquefaction reactivity of Xiaolongtan lignite with different Fe-based catalysts and the results showed that $\mathrm{Fe}+\mathrm{S}$ catalyst produced the highest gas and oil yields compared to $\mathrm{FeS}$ and $\mathrm{SO}_{4}{ }^{2-} / \mathrm{ZrO}_{2}$ catalyst. Monterroso et al. [8] conducted coal gasification experiments by adding composite Fe-sodium catalyst, by which the carbon conversion rate was dramatically increased at 700 to $800{ }^{\circ} \mathrm{C}$ and the yields of $\mathrm{H}_{2}$ and $\mathrm{CO}$ at $800{ }^{\circ} \mathrm{C}$ also increased by $15 \%$ and $40 \%$, respectively. Sowa et al. [9] studied the effect of four different kinds of natural iron ores in catalytic pyrolysis of coal to produce light aromatic hydrocarbons. With the limonite addition, light aromatics production increased remarkably due to its excellent deoxygenation ability. The interaction between the coal structure and the catalyst in the pyrolysis process is vital for the development of new catalytic pyrolysis technology and the design of high efficiency catalyst. Many researchers have tried to obtain the catalytic mechanism with various apparatus $[10,11]$. Nonetheless, no defined interpretation has been established because of the complex composition of coal, as well as the multiple reactions in the pyrolysis process.

An attractive way to study the catalytic pyrolysis mechanism of lignite is to use model compounds. Sekiguchi et al. [12] studied the effect of basic $\mathrm{CaO}$ on the pyrolysis of bibenzyl, and it was found that toluene was the primary product with the catalyst while stilbene was the primary product without the catalyst. Wang et al. [13] performed a theoretical study on the catalytic pyrolysis of benzoic acid with or without four different metallic oxides using the periodic density functional theory (DFT) calculation. Song et al. [14] conducted a hydropyrolysis of phenethyl phenyl ether over an Ni-based catalyst, and found that the noble catalyst exhibited a high level of $\mathrm{C}-\mathrm{O}$ bond cracking selectivity. Ordinary model compounds can only be adopted to study specific chemical bonds with selective catalysts under the thermal process, and hardly exhibit all the information that takes part in coal pyrolysis owing to the simple structures and single reactions.

According to the fixed-mobile model of coal, the mobile fractions trapped in coal can be removed by organic solvent extraction. Given that the extraction yield strongly relies on the solvent, tetrahydrofuran (THF) has been extensively chosen for its powerful extraction ability [15]. As reported, the extracting yield using THF was 5.09\% (Huolinghe lignite) [16], 5.5\% (Loy Yang lignite) [17], 6.58\% (high-sulfur bituminous coal) [18], and as high as $25 \%$ (Australian coals) [19]. In this regard, THF was also chosen in this study since it enables the dissolution of mobile fractions of coal as thoroughly as possible. As extracted from raw coal, the mobile fractions could partially reflect the characteristics and molecular weight distributions of the parent coal during the heating treatment [20]. Therefore, a promising approach to elucidate the catalytic mechanism of raw coal is to study the reactivity of extracts with/without catalyst. As far as we know, current research on the catalytic pyrolysis of extracts has rarely been presented. In this study, the reactivity of extracts with/without catalysts were studied by thermogravimetry with mass spectrometry (TG-MS), which provided deep insight into the sensitive thermal reactions and simultaneous volatile information about the physical and chemical nature of fossil fuels using thimbleful samples (milligram level) in a specific thermal event [21].

The aim of the current study was to elucidate the interaction between the coal structure and catalyst by using THF extracts as model compounds instead of conventional simple compounds, which will benefit the development of new catalytic pyrolysis technology and the design of high efficiency catalysts. In this work, $\mathrm{Fe}\left(\mathrm{NO}_{3}\right)_{3} \cdot 9 \mathrm{H}_{2} \mathrm{O}$ and $\mathrm{FeCl}_{3} \cdot 6 \mathrm{H}_{2} \mathrm{O}$ were used as Fe-based catalysts, which are noted as $\mathrm{Fe}(\mathrm{N})$ and $\mathrm{Fe}(\mathrm{C})$, respectively. THF was employed to exhaustively extract the mobile phase from the lignite. The composition of the extracts was analyzed by comprehensive two-dimensional gas chromatography mass spectrometry (GC $\times$ GC-MS). The thermal behaviors and product distributions of the extracts with/without catalyst were investigated by TG-MS. The kinetic parameters during pyrolysis were also established to gain a deeper insight into the catalytic mechanism. 


\section{Results and Discussions}

\subsection{Proximate and Ultimate Analyses}

Table 1 shows the proximate and ultimate analyses of the samples. A higher hydrogen to carbon $(\mathrm{H} / \mathrm{C})$ and oxygen to carbon $(\mathrm{O} / \mathrm{C})$ ratio was exhibited in extracts $(\mathrm{EX})$ in contrast with raw coal $(\mathrm{RC})$ and residue (RE), indicating that THF treatment was efficient in removing the O-containing compounds from RC. Apart from that, a higher $\mathrm{H} / \mathrm{C}$ ratio in EX implies that it contains more aliphatics and/or long aliphatic side chains. The lower volatile content of RE is attributed to the removal of EX, implying that EX plays an important role in the devolatilization reactions in coal pyrolysis.

Table 1. Proximate analyses and ultimate analyses.

\begin{tabular}{|c|c|c|c|c|c|c|c|c|c|c|}
\hline \multirow{2}{*}{ Samples } & \multicolumn{3}{|c|}{ Proximate Analyses (wt \%) } & \multicolumn{5}{|c|}{ Ultimate Analyses (wt \%, daf) } & \multicolumn{2}{|c|}{ Atomic Ratio } \\
\hline & $\mathbf{M}_{\mathrm{ad}}$ & $\mathbf{A}_{\mathbf{d}}$ & $\mathrm{V}_{\mathrm{d}}$ & $\mathrm{C}$ & $\mathbf{H}$ & $\mathbf{N}$ & $S$ & $\mathrm{O}^{*}$ & $\mathrm{H} / \mathrm{C}$ & $\mathrm{O} / \mathrm{C}$ \\
\hline $\mathrm{RC}$ & 15.81 & 9.93 & 57.69 & 63.46 & 4.73 & 2.08 & 0.92 & 28.81 & 0.894 & 0.340 \\
\hline RE & 11.39 & 10.35 & 55.38 & 64.83 & 4.38 & 2.04 & 0.96 & 27.79 & 0.811 & 0.321 \\
\hline EX & - & - & - & 51.69 & 12.34 & 0.73 & 1.08 & 34.16 & 2.865 & 0.496 \\
\hline
\end{tabular}

* by difference.

\subsection{GC $\times G C-M S$ Analysis of Extracts}

Figure 1 illustrates a colorized chromatogram of a total intensity chromatogram (TIC) of EX. In the chromatogram, the $\mathrm{X}$-axis is the volatility-based retention time ( $\mathrm{min})$, the $\mathrm{Y}$-axis is the polarity-based retention time (s), and the Z-axis is the MS response, which appears as a spot, and its intensity value is displayed by color variation from low (blue) to high (red). The properties of the detected compounds were identified using the National Institute of Standards and Technology (NIST11) library. More than 100 compounds in EX can be well separated and detected using a mass spectrum similarity greater than $70 \%$ and a signal-to-noise ratio greater than 500 . Here, 55 main compounds were identified as the numbered spots, and are listed in Table S1 (in the Supplementary Materials), which are largely grouped into aromatics, aliphatics, and oxygenated compounds. It can be seen that in Figure 2, the highest content of oxygenated compounds was detected in EX, including phenols, alcohol, ketone, and acid, with a relative content of $55.35 \%$. This result is in good agreement with the literature [18]. It is believed that the oxygenated compounds were extracted by the electronic donor acceptor bonds' and hydrogen bonds' interaction between the THF and O-containing structures of the coal [18,22]. The total aromatic content ranging from one ring to four rings is $26.02 \%$. Additionally, most of the remaining components were aliphatic hydrocarbons, which were composed of straight chain alkanes and alkenes. 


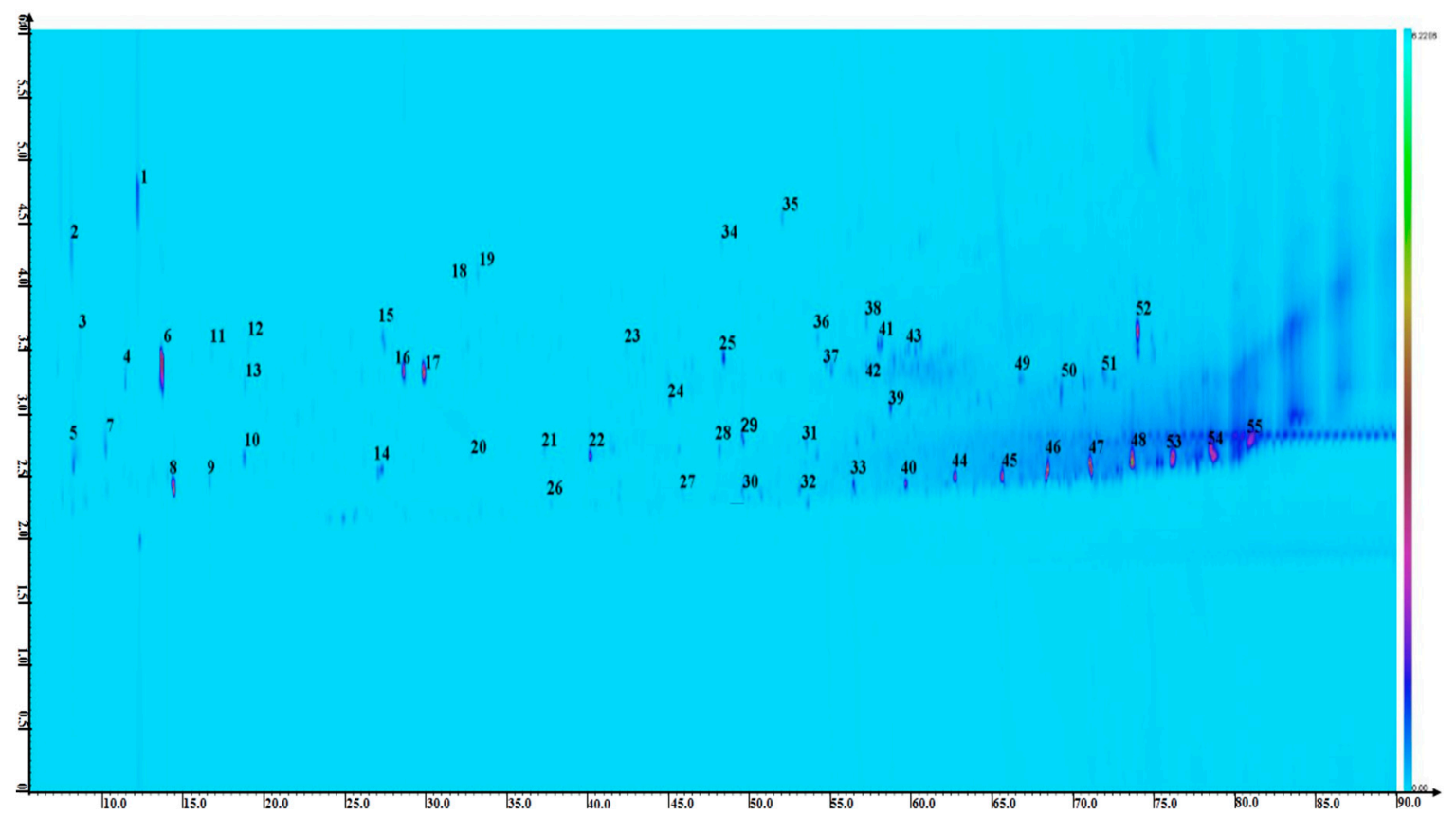

Figure 1. A colorized chromatogram of a total ion chromatography of extracts.

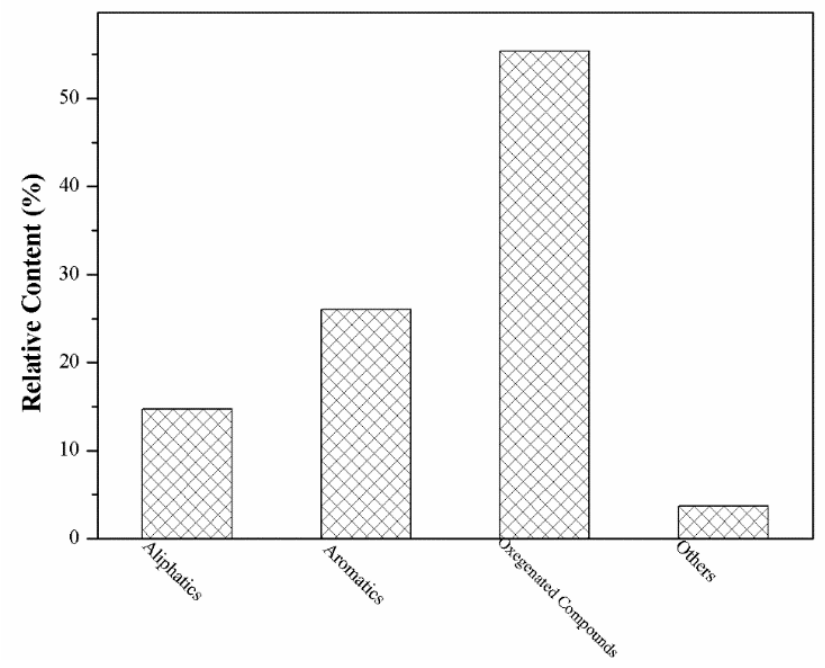

Figure 2. The content of different chemical groups in EX.

\subsection{TG-MS Analysis of Extract with/without Catalyst}

\subsubsection{Thermal Behaviors of Extract with/without Catalyst}

To explain the characteristics and remove the mass loss of catalyst in the pyrolysis process, TG analyses of pure catalysts was carried out under the same experimental condition. As shown in Figure 3a, two obvious DTG peaks of $\mathrm{Fe}(\mathrm{N})$ were observed during the whole thermal treatment. The first mass lose stage between 80 and $120^{\circ} \mathrm{C}$ resulted from the dehydration reaction, and the other dramatic peak around $150^{\circ} \mathrm{C}$ was ascribed to the decomposition of $\mathrm{Fe}(\mathrm{N})$. The DTG results of $\mathrm{Fe}(\mathrm{C})$ (Figure $3 \mathrm{~b}$ ) showed that a dramatic peak occurred at about $100^{\circ} \mathrm{C}$ because of the crystal water removal, and the other two peaks appeared at 205 and $380{ }^{\circ} \mathrm{C}$, respectively, indicating that more complicated chemical reactions and changeable iron species occurred for $\mathrm{Fe}(\mathrm{C})$ in the thermal process, which is in agreement with that reported by Yamashita and Tomita [23,24]. 


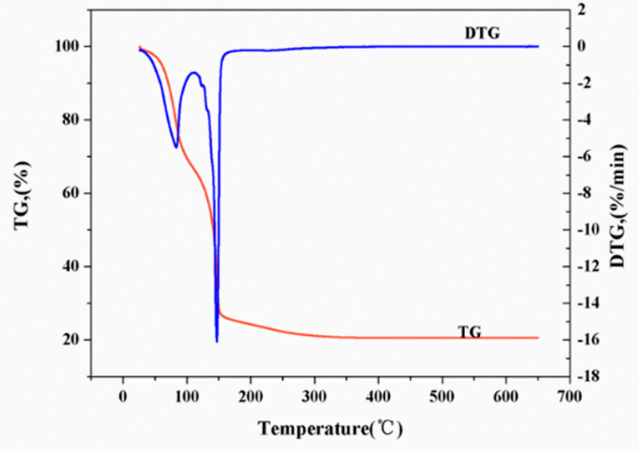

(a)

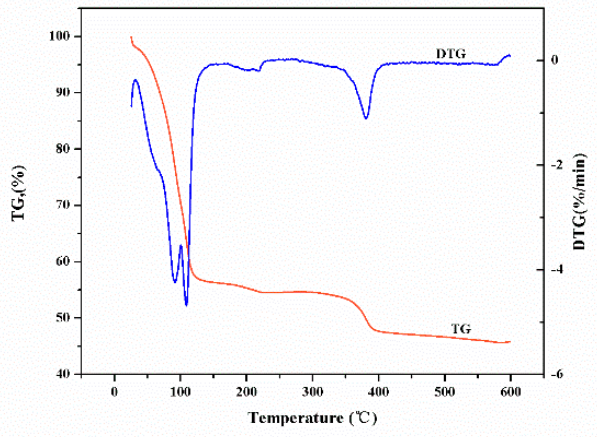

(b)

Figure 3. (a) TG-DTG analysis of Fe(N); (b) TG-DTG analysis of Fe(C).

For pyrolysis of EX without catalyst (Figure 4a), approximately $77.88 \%$ of the compounds contained in EX were removed before $700{ }^{\circ} \mathrm{C}$, for which the residual yield remained almost unchanged. Here, an unchanged residual yield temperature was defined as the final temperature. In the pyrolysis process, it is commonly recognized that compounds in EX evaporate to form tar, decompose to generate gas, and even repolymerize into larger molecules [18]. TGA curves of EX-Fe(N) and EX-Fe(C) were derived by deducting the mass loss of pure catalyst proportionally. By the separate addition of $5 \mathrm{wt} \% \mathrm{Fe}(\mathrm{N})$ and $\mathrm{Fe}(\mathrm{C})$, the conversion of EX improved to $84.38 \%$ and $89.66 \%$ at the final temperature. Moreover, the final temperature was decreased to 650 and $550{ }^{\circ} \mathrm{C}$, respectively. Evidently, the catalytic influence of Fe-based catalyst lead to the rise of EX conversion and reduction of the final temperature. Multiple studies [25-27] showed that Fe-based catalysts have the capability of cracking the long-chain aliphatic hydrocarbons and lowering the bond energy, thereby making the pyrolysis reaction occur at lower temperature.
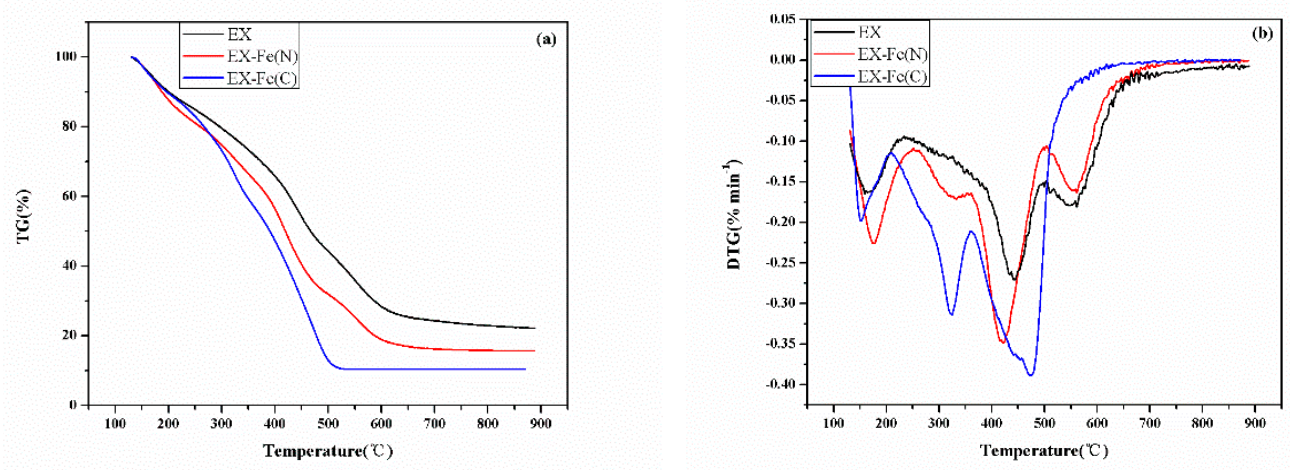

Figure 4. (a) TGA curve of EX with/without catalyst; (b) DTG curve of EX with/without catalyst.

As shown in Figure $4 \mathrm{~b}$, a DTG peak emerged at about $200{ }^{\circ} \mathrm{C}$, which was similar for three samples, and resulted from the evaporation of small molecules at a low boiling point. The maximum weight loss for the three samples occurred at around $450{ }^{\circ} \mathrm{C}$ due to the removal of volatiles and the decomposition reactions. Different from EX, an obvious DTG peak appeared for EX-Fe(N) and $\mathrm{EX}-\mathrm{Fe}(\mathrm{C})$ at about $300^{\circ} \mathrm{C}$, thus it can be concluded that the addition of $\mathrm{Fe}(\mathrm{N})$ and $\mathrm{Fe}(\mathrm{C})$ facilitated some stable chemical bonds in EX cracking at lower temperatures. An obvious difference between EX-Fe(N) and EX-Fe(C) was that nearly no mass loss appeared at around $550{ }^{\circ} \mathrm{C}$ for $\mathrm{EX}-\mathrm{Fe}(\mathrm{C})$, suggesting that $\mathrm{Fe}(\mathrm{N})$ and $\mathrm{Fe}(\mathrm{C})$ exhibited different catalytic performances in the pyrolysis of EX. Given the diversity of mass loss stages, the mass loss ratio in different temperature regions $\left(100-200{ }^{\circ} \mathrm{C}, 200-350{ }^{\circ} \mathrm{C}, 350-500{ }^{\circ} \mathrm{C}, 500-600{ }^{\circ} \mathrm{C}\right)$ for the three samples are illustrated in Figure 5. The mass loss ratio in the first temperature region $\left(100-200^{\circ} \mathrm{C}\right)$ remained constant for the three samples, which was attributed to the evaporation of substances at 
the low boiling point. In the second temperature region, the mass loss ratio of EX, EX-Fe(N), and $\mathrm{EX}-\mathrm{Fe}(\mathrm{C})$ was $16.35 \%, 21.57 \%$, and $30.12 \%$, respectively. In the temperature region $350-500{ }^{\circ} \mathrm{C}$, the mass loss ratio of EX-Fe(N) and EX-Fe(C) increased to $34.75 \%$ and $46.29 \%$ in contrast with $29.58 \%$ for EX. On the contrary, in the temperature region $500-600{ }^{\circ} \mathrm{C}$, the mass loss ratio of EX decreased from $17.93 \%$ to $14.21 \%$ and $3.08 \%$ for $\mathrm{EX}-\mathrm{Fe}(\mathrm{N})$ and $\mathrm{EX}-\mathrm{Fe}(\mathrm{C})$. It is believed that the reactions in a certain temperature range are generally related to the cleavage of specific chemical bonds in coal pyrolysis, and the decomposition of $\mathrm{C}_{\mathrm{ar}}-\mathrm{C}_{\mathrm{al}}$ and $\mathrm{C}_{\mathrm{ar}}-\mathrm{O}$ structures generally occurs at temperatures above $550{ }^{\circ} \mathrm{C}$ [28]. Fu et al. [5] considered that Fe-based catalyst facilitated the decomposition of aliphatic chains and O-containing structures, thereby the weight loss for $\mathrm{EX}-\mathrm{Fe}(\mathrm{N})$ and $\mathrm{EX}-\mathrm{Fe}(\mathrm{C})$ dramatically increased in the temperature range $200-500{ }^{\circ} \mathrm{C}$. Yamashita et al. [24] studied the local structures of $\mathrm{Fe}\left(\mathrm{NO}_{3}\right)_{3}$ and $\mathrm{FeCl}_{3}$ during the thermal treatment of iron-loaded brown coal. The iron species of $\mathrm{Fe}\left(\mathrm{NO}_{3}\right)_{3}$ were exhibited mainly as atomically dispersed Fe or ultrafine $\mathrm{FeOOH}$ blow $650{ }^{\circ} \mathrm{C}$, while that of $\mathrm{FeCl}_{3}$ easily aggregated to crystalline $\mathrm{FeO}$ at $500{ }^{\circ} \mathrm{C}$. Moreover, Zhao et al. [29] demonstrated that ferrous ions, such as $\mathrm{Fe}_{3} \mathrm{O}_{4}$ and $\mathrm{FeO}$, possessed a better catalytic effect for cracking the coal structure in the pyrolysis, which is due to the mass loss ratio of $\mathrm{EX}-\mathrm{Fe}(\mathrm{C})$ being enlarged more than that of $\mathrm{EX}-\mathrm{Fe}(\mathrm{N})$ after the temperature reached $450{ }^{\circ} \mathrm{C}$.

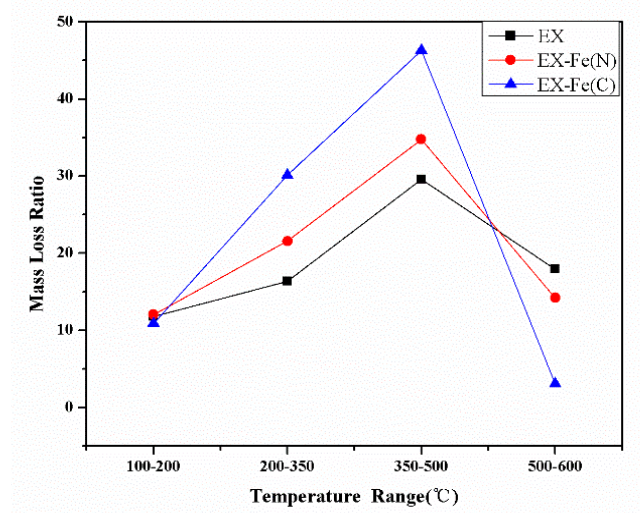

Figure 5. Mass loss ratios of EX with/without catalyst in different temperature ranges.

\subsubsection{Evolution of Gaseous Products}

The evolution of gaseous products for EX with/without catalyst are shown in Figure 6a-j. It is clearly observed that the evolution curve of $\mathrm{CH}_{4}$ for EX can be divided into two steps. The first step was assigned to the temperature range $300-500{ }^{\circ} \mathrm{C}$, where $\mathrm{CH}_{4}$ generation started at about $300{ }^{\circ} \mathrm{C}$, followed by a sharp rise trend, achieving a maximum value at around $450{ }^{\circ} \mathrm{C}$. This step resulted from the breakage of long chain aliphatics. The second stage lasted from $500{ }^{\circ} \mathrm{C}$ until the final temperature, where the evolution peak appeared at about $550^{\circ} \mathrm{C}$, which was attributed to demethylation of methoxyl groups [30]. By the separate addition of $\mathrm{Fe}(\mathrm{N})$ and $\mathrm{Fe}(\mathrm{C})$, a slight $\mathrm{CH}_{4}$ evolution appeared in the temperature range $100-200{ }^{\circ} \mathrm{C}$, which was nearly invisible for $\mathrm{EX}$, indicating that $\mathrm{Fe}(\mathrm{N})$ and $\mathrm{Fe}(\mathrm{C})$ evidently facilitate the cleavage of aliphatic chains, with small radicals $\left(\mathrm{CH}_{3}\right.$ and $\left.\mathrm{H} \cdot\right)$ formation, and then rapid stabilization with each other. For this reason, $\mathrm{H}_{2}$ (Figure $6 \mathrm{~b}$ ) also appeared in this temperature range for $\mathrm{EX}-\mathrm{Fe}(\mathrm{N})$ and $\mathrm{EX}-\mathrm{Fe}(\mathrm{C})$. It is reasonably concluded that $\mathrm{EX}$ acts as the hydrogen donors during the catalytic pyrolysis of coal [18]. The evolution peaks around $400{ }^{\circ} \mathrm{C}$ for $\mathrm{EX}-\mathrm{Fe}(\mathrm{N})$ and $\mathrm{EX}-\mathrm{Fe}(\mathrm{C})$ exhibited a slight difference in comparison with that of $\mathrm{EX}$, which may be due to the different properties of $\mathrm{Fe}(\mathrm{N})$ and $\mathrm{Fe}(\mathrm{C})$ on the catalytic fracture of aliphatic chains into $\mathrm{CH}_{4}$. The second peak for $\mathrm{EX}-\mathrm{Fe}(\mathrm{N})$ and $\mathrm{EX}-\mathrm{Fe}(\mathrm{C})$ was clearly strengthened, along with a decrease in their peak temperature from 600 to 550 and $505{ }^{\circ} \mathrm{C}$, respectively, which evidently resulted from the positive influence of the Fe-based catalysts on the decomposition of the methoxyl groups. 
Catalysts 2019, 9, 953

7 of 14
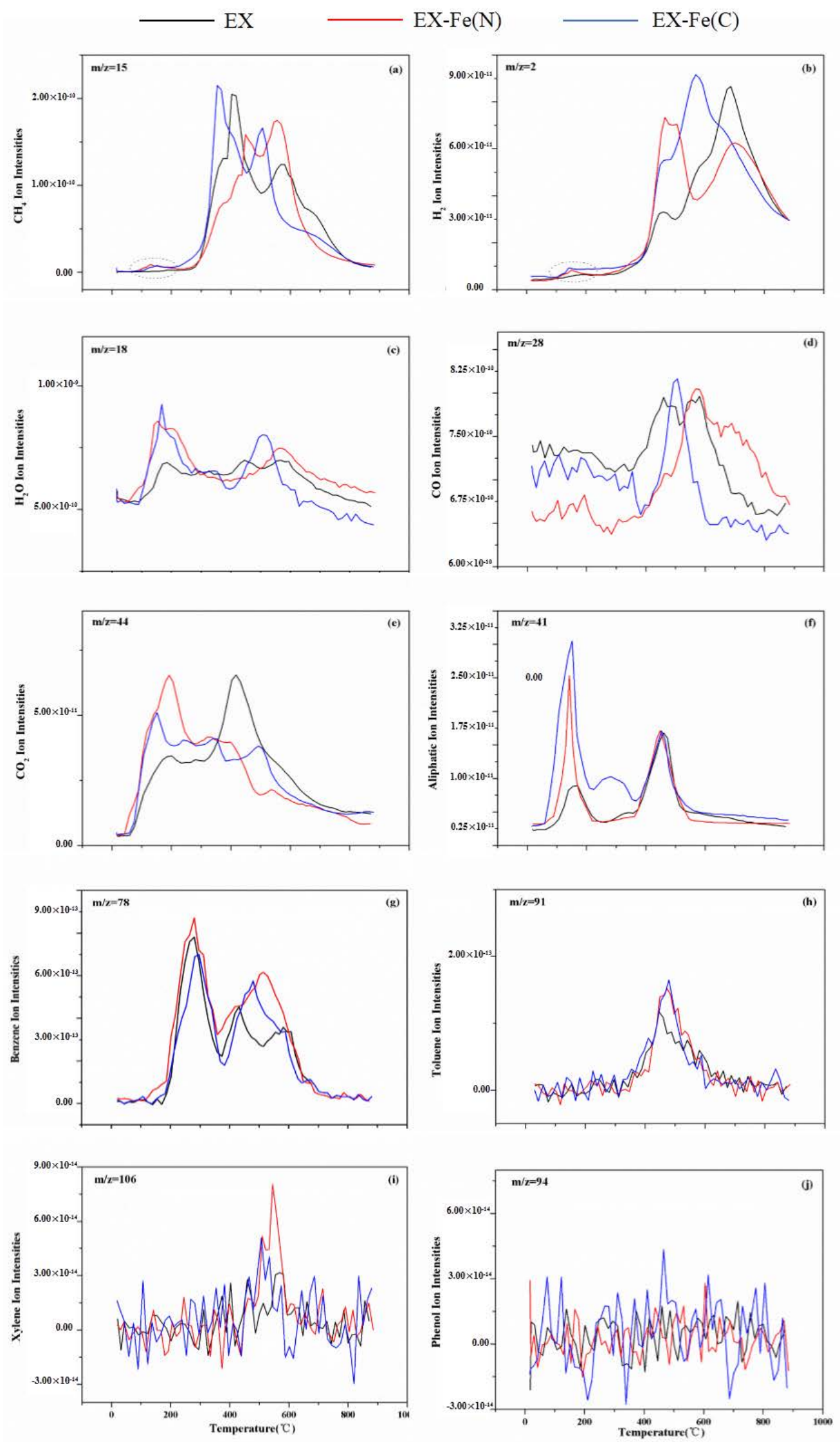

Figure 6. Evolution products during thermal treatment of EX with/without catalyst: (a) $\mathrm{CH}_{4}$; (b) $\mathrm{H}_{2}$; (c) $\mathrm{H}_{2} \mathrm{O}$; (d) $\mathrm{CO}$; (e) $\mathrm{CO}_{2}$; (f) aliphatics; (g) benzene; (h) toluene; (i) xylene; and (j) phenol. 
The evolution of $\mathrm{H}_{2}$ for EX also comprised two steps (Figure 6b). In the first step, $\mathrm{H}_{2}$ was released in the temperature range $300-500{ }^{\circ} \mathrm{C}$, which followed a radical mechanism. Small radicals produced from the decomposition of side chains and/or alkyl chains connected to aromatic structures can stabilize with each other to form aliphatic hydrocarbons, $\mathrm{H}_{2}$ and $\mathrm{CH}_{4}$, which is evidence of the phenomenon that $\mathrm{H}_{2}, \mathrm{CH}_{4}$, and aliphatic hydrocarbons are simultaneously generated for EX in such a temperature range [21]. In the second step, abundant $\mathrm{H}_{2}$ was generated from the condensation of aromatics above $600{ }^{\circ} \mathrm{C}$ [31]. For EX-Fe(N) and EX-Fe(C), the initial formation of $\mathrm{H}_{2}$ appeared at about $150{ }^{\circ} \mathrm{C}$, and the intensities were evidently strengthened in the temperature range $400-500^{\circ} \mathrm{C}$, but decreased at about $600^{\circ} \mathrm{C}$, as Fe-based catalysts clearly promoted the breakage of aliphatic chains at lower temperatures, thereby making the reaction more available. This conclusion is confirmed by the fact that EX-Fe(N) and $\mathrm{EX}-\mathrm{Fe}(\mathrm{C})$ exhibited a greater mass loss ratio at 350 to $500{ }^{\circ} \mathrm{C}$, and a smaller mass loss ratio after $500{ }^{\circ} \mathrm{C}$ in contrast with EX.

The evolution of $\mathrm{H}_{2} \mathrm{O}$ at low temperatures $\left(<200{ }^{\circ} \mathrm{C}\right)$ mainly came from the moisture of the samples [32]. $\mathrm{H}_{2} \mathrm{O}$ normally results from the degradation of $\mathrm{O}$-containing functional groups above $20{ }^{\circ} \mathrm{C}$. It is generally accepted that the thermal stability of O-containing functional groups is in the order of $-\mathrm{OH}>-\mathrm{O}->-\mathrm{C}=\mathrm{O}>-\mathrm{COOH}>-\mathrm{CHO}[16,33]$. The aldehyde group and carboxyl group are active O-containing structures, which are easily degraded below $300^{\circ} \mathrm{C}$ [16]. Carbonyl groups and ether bonds are usually decomposed in the temperature range $350-550^{\circ} \mathrm{C}$ [33]. Aromatic hydroxyl is a relatively steady $\mathrm{O}$-containing functional group, which generally fractures above $700{ }^{\circ} \mathrm{C}$ [16]. Here, the $\mathrm{H}_{2} \mathrm{O}$ evolution curve for EX was distributed in a wide temperature range, where the initial peak appeared at around $100^{\circ} \mathrm{C}$ for the removal of external moisture, and then achieved three peaks at about 185,450 , and $570^{\circ} \mathrm{C}$, which accounted for the breakage of the aldehyde group and/or carboxyl group, carbonyl groups, and ether bonds, respectively. For EX-Fe(N) and $\mathrm{EX}-\mathrm{Fe}(\mathrm{C})$, the evolution peak of $\mathrm{H}_{2} \mathrm{O}$ was clearly enlarged at around $185^{\circ} \mathrm{C}$, while simultaneously the peak at about $450{ }^{\circ} \mathrm{C}$ disappeared in comparison with EX, implying that Fe-based catalysts facilitated the degradation of carbonyl groups at lower temperatures. The peak at around $570{ }^{\circ} \mathrm{C}$ was dramatically strengthened for $\mathrm{EX}-\mathrm{Fe}(\mathrm{N})$, and the peak temperature decreased to $500{ }^{\circ} \mathrm{C}$ for $\mathrm{EX}-\mathrm{Fe}(\mathrm{C})$. Moreover, the evolution trend of $\mathrm{H}_{2} \mathrm{O}$ was strongly close to that of $\mathrm{CH}_{4}$ in the temperature range $400-600{ }^{\circ} \mathrm{C}$, which further proved that Fe-based catalysts effectively promoted the decomposition of methoxy groups.

Similar $\mathrm{CO}$ evolution trends are shown in Figure $6 \mathrm{~d}$ for the three samples during the whole thermal process. Nearly no $\mathrm{CO}$ was produced until the temperature reached $300{ }^{\circ} \mathrm{C}$, and then maximum production was achieved at around $500^{\circ} \mathrm{C}$, but finally stopped after $600^{\circ} \mathrm{C}$. CO formation also resulted from the breakdown of oxygenated functional groups. The major tar molecules were released at around $500{ }^{\circ} \mathrm{C}$ during the pyrolysis of coal [32], thereby it is reasonably inferred that CO evolution in this temperature range is mainly attributed to the secondary fracture of O-containing structures in volatile molecules for the three samples, and the catalysts possessed a slight influence in the secondary reactions.

The source of $\mathrm{CO}_{2}$ generated during pyrolysis at low temperatures generally comes from three aspects, i.e., adsorbed $\mathrm{CO}_{2}$, breakage of carboxyl groups, and cleavage of some stable O-containing structures [30]. For EX, $\mathrm{CO}_{2}$ was originally generated at about $100^{\circ} \mathrm{C}$ for the removal of adsorbed $\mathrm{CO}_{2}$, with a stable rising trend, and reached its first peak at around $300^{\circ} \mathrm{C}$, which was attributed to the breaking of carboxyl functional groups, and then achieved maximum production at around $400^{\circ} \mathrm{C}$ for the cracking of stable O-containing heterocycles (Figure 6e). For EX-Fe(N) and EX-Fe(C), a large amount of $\mathrm{CO}_{2}$ formation was observed to $200{ }^{\circ} \mathrm{C}$, and $\mathrm{CO}_{2}$ evolution decreased at around $400{ }^{\circ} \mathrm{C}$, which indicates that the Fe-based catalysts evidently promoted the breakage of carboxyl functional groups at lower temperatures. This is consistent with the conclusion that $\mathrm{CO}_{2}$ yield is dramatically increased by the presence of Fe-based catalysts in the literature [5].

The fragment of $\mathrm{C}_{3} \mathrm{H}_{5}{ }^{+}(\mathrm{m} / \mathrm{z}=41)$ was chosen to study the development characteristics of light aliphatics since $\mathrm{C}_{3} \mathrm{H}_{5}{ }^{+}$had a sharp peak with an even shape in the aliphatic hydrocarbon mass spectrum [30,34]. As shown in Figure 6f, similar evolution trends were observed for the three samples, 
where the first slight peak appeared at approximately at $130^{\circ} \mathrm{C}$, and the second strong peak appeared at about $450{ }^{\circ} \mathrm{C}$. Accordingly [30], the evolution of aliphatic hydrocarbons at around $450{ }^{\circ} \mathrm{C}$ mainly resulted from the degradation of straight chain paraffin, aromatic side chains, and some $\mathrm{C}_{\mathrm{ar}}-\mathrm{O}-\mathrm{C}_{\mathrm{al}} / \mathrm{C}_{\mathrm{al}}-\mathrm{O}-\mathrm{C}_{\mathrm{al}}$ structures in the coal. The first peak at around $130^{\circ} \mathrm{C}$ was caused by the evaporation of small molecules at the low boiling point. Despite the evolution temperature being almost the same for the three samples, the intensities of $\mathrm{EX}-\mathrm{Fe}(\mathrm{N})$ and $\mathrm{EX}-\mathrm{Fe}(\mathrm{C})$ were much stronger than that of $\mathrm{EX}$, suggesting that the cracking of aliphatic structures can be promoted by the presence of Fe-based catalysts, and $\mathrm{Fe}(\mathrm{C})$ possessed a better catalytic reactivity.

The evolution curves of benzene, toluene, xylene, and phenol are illustrated in Figure $6 \mathrm{~g}-\mathrm{j}$. For the evolution of toluene and xylene, an analogous single peak appeared at nearly $500{ }^{\circ} \mathrm{C}$ for three samples, while the intensities of $\mathrm{EX}-\mathrm{Fe}(\mathrm{N})$ and $\mathrm{EX}-\mathrm{Fe}(\mathrm{C})$ were much stronger than that of EX. Such an evolution trend was strongly close to the second evolution peak of aliphatic hydrocarbon (Figure $6 \mathrm{f}$ ), indicating that the cracking of aliphatic side chains connected to aromatic structures can be promoted by the presence of Fe-based catalysts at about $500{ }^{\circ} \mathrm{C}$, leading to the generation of more aliphatic and aromatic fragments, which is evidence of the phenomenon that a higher amount of toluene and xylene radicals, along with aliphatic units, emerged in this temperature range for $\mathrm{EX}-\mathrm{Fe}(\mathrm{N})$ and $\mathrm{EX}-\mathrm{Fe}(\mathrm{C})$. It is considered that phenol was generated from the decomposition of aryl ether bonds or monohydric phenolic structure, and then stabilization with $\mathrm{H}$. [35]. It was observed that nearly no phenol was generated during the whole thermal process for three samples, indicating that monohydric phenolic structure and/or aryl ether bond were decomposed to form other products, rather than a combination with $\mathrm{H}$.

\subsection{Kinetic Analysis}

Ex was selected as a respective sample to show the curve of the thermal process at different heating rates $\left(10,20\right.$, and $\left.40^{\circ} \mathrm{C} / \mathrm{min}\right)$ from 120 to $900^{\circ} \mathrm{C}$, and the plot of the DAEM method, which are exhibited in Figures 7 and 8, respectively. The thermal curves and DAEM plot for EX-Fe(N) and EX-Fe(C) are shown in Figures S1-S4, respectively (in the Supplementary Materials). $E$ and $A$ values at different conversions were calculated and are listed in Table S2. High correlation coefficients (higher than 0.9) were obtained for three samples, suggesting that the DAEM method could provide good fitting effects. With the conversion ratio changing from 0.1 to 0.9 , the $E$ value of EX also increased from 74.31 to 286.03 $\mathrm{kJ} / \mathrm{mol}$. The $E$ mean different bond energies of species in EX during the thermal process. Additionally, the variations of $A$ and $E$ showed the same trend, indicating the existence of a compensation effect between $A$ and $E$ [4]. The mean value of $E$ and $A$ for the three different samples are listed in Table 2. The average $E$ value of EX was $146.63 \mathrm{~kJ} / \mathrm{mol}$, which was higher than $E(98.1 \mathrm{~kJ} / \mathrm{mol})$ [36] obtained via the DAEM method in the thermal process of the mobile fractions from a lignite by using NMP/CS mixed solvent extraction. This might be due to the heavier components extracted by THF. However, the average value of $E$ for different coals were 180 [36] and $192 \mathrm{~kJ} / \mathrm{mol}$ [37], respectively, which were higher than the average $E$ of EX in this study, suggesting EX was more easily pyrolyzed than raw coal during the thermal process. With the separate addition of $\mathrm{Fe}(\mathrm{N})$ and $\mathrm{Fe}(\mathrm{C})$, the average value of EX-Fe(N) and EX-Fe(C) was obviously decreased to 122.17 and $102.39 \mathrm{~kJ} / \mathrm{mol}$, respectively, indicating that Fe-based catalysts facilitate the cracking of EX, leading to an increase in EX reactivity, and making the pyrolysis reactions more available. Moreover, the catalytic effect of $\mathrm{Fe}(\mathrm{C})$ was higher than $\mathrm{Fe}(\mathrm{N})$, which may be due to the appearance of ferrous ion $[24,29]$ in the thermal treatment of $\mathrm{Fe}(\mathrm{C})$. 


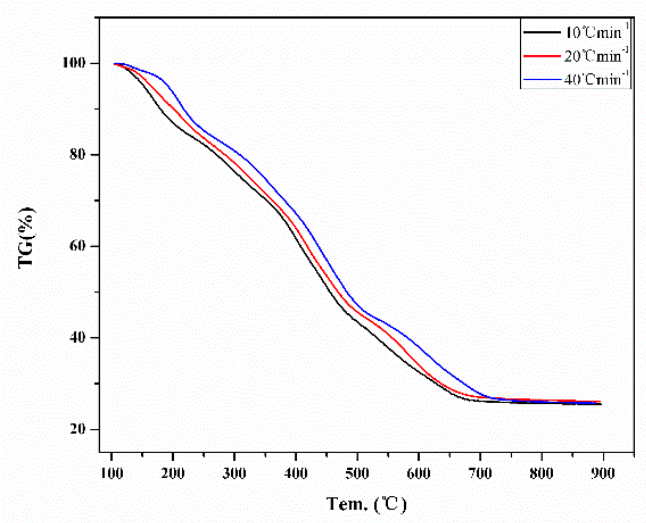

Figure 7. TGA curve of EX at different heating rates.

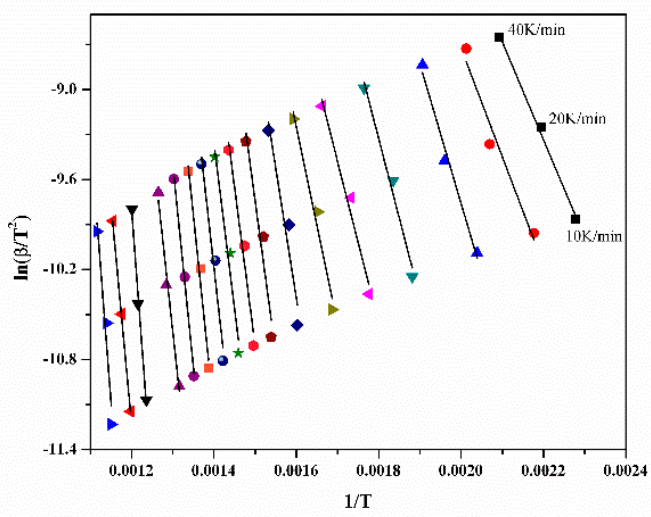

Figure 8. Arrhenius plots of the DAEM method for EX.

Table 2. Mean value of $E$ and $A$ for three different samples.

\begin{tabular}{|c|c|c|}
\hline & $E(\mathrm{~kJ} / \mathrm{mol})$ & $A\left(\min ^{-1}\right)$ \\
\hline EX & 146.63 & $4.57 \times 10^{8}$ \\
\hline $\mathrm{EX}-\mathrm{Fe}(\mathrm{N})$ & 122.17 & $1.32 \times 10^{8}$ \\
\hline $\mathrm{EX}-\mathrm{Fe}(\mathrm{C})$ & 102.39 & $1.45 \times 10^{4}$ \\
\hline
\end{tabular}

\section{Experiments}

\subsection{Experimental Procedures}

Raw coal sample was selected from Yunnan Province, China. Before use, the sample was pulverized and sieved to blow 80 mesh, and then dried at $105{ }^{\circ} \mathrm{C}$ for $2 \mathrm{~h}$.

THF was chosen as the extraction solvent in this experiment. Raw coal (10 $\pm 0.1 \mathrm{~g})$ and $250 \mathrm{~mL}$ of THF were added to Soxhlet vessel. The apparatus was heated in a water bath at $80{ }^{\circ} \mathrm{C}$, then the experiment was halted when the solvent became colorless. After extraction, the solution was condensed in a rotary evaporator. The soluble fraction obtained from the Yunnan lignite was 7.21\%, which was calculated at the extract-to-coal weight ratio on a dry basis. In addition, raw coal, residue, and extracts are abbreviated as RC, RE, and EX. Before TG-MS analysis, the extracts and the catalysts Fe(N) and $\mathrm{Fe}(\mathrm{C})$ were homogeneously mixed at a weight ratio of 5:100 by mixing $50 \mathrm{mg}$ of salt (without crystal water) with $1 \mathrm{~g}$ of extracts, which are respectively denoted as $\mathrm{EX}-\mathrm{Fe}(\mathrm{N})$ and $\mathrm{EX}-\mathrm{Fe}(\mathrm{C})$.

\subsection{GCXGC-MS Analysis}

GC $\times$ GC-MS is a more effective equipment for analyzing complex samples than traditional GC-MS. Hundreds/thousands of analytes can be fully separated and detected from the sample matrix by using 
GC $\times$ GC-MS $[38,39]$. In this work, an Agilent 7890B gas chromatograph coupled with a 5977A mass spectrometer (Agilent Technologies, Santa Clara, CA, USA) and an extra ZX10542 thermal modulator (ZOEX Corporation, Houston, TX, USA) were assembled in a GCXGC-MS system. High purity helium $(99.999 \%)$ was used as the carrier gas. It was employed to analyze the THF extract, and its detailed operational programs are referenced in our previous study [40].

\subsection{TG-MS Analysis}

TG-MS was used to examine the thermal behavior and detect the volatile product distribution during the thermal treatment. In this work, TG-MS experiments were performed using a thermal analyzer (Setsys Evolution 24, SETARAM, Caluire-et-Cuire, France) combined with a mass spectrometer (HPR20, Hider, Hull, UK) with Ar purging at $100 \mathrm{~mL} / \mathrm{min}$. Approximately $10 \mathrm{mg}$ of sample was heated from room temperature to $900{ }^{\circ} \mathrm{C}$ at $10^{\circ} \mathrm{Cmin}^{-1}$. The released volatile species, including $\mathrm{H}_{2}, \mathrm{CH}_{4}, \mathrm{CO}$, $\mathrm{CO}_{2}, \mathrm{H}_{2} \mathrm{O}$ and some non-condensed aliphatics and aromatics, such as benzene, toluene, xylene, and phenol, were measured.

\subsection{Kinetic Analysis}

To gain a deeper insight into the influence of Fe-based catalysts on the extract during the whole thermal process, a non-isothermal method of the distributed activation energy model (DAEM) [41,42] was adopted in this study. DAEM assumes that the pyrolysis of solid-state samples consists of a series of first-order parallel irreversible reactions, each of which has its own activation energy, all of which exhibit a certain continuous distribution. The resulting DAEM equation of solid-state materials during heating treatment can be described as:

$$
1-\frac{V}{V^{*}}=\int_{0}^{\infty} \exp \left(-A \int_{0}^{t} \exp \left(-\frac{E}{R T}\right) d t\right) f(E) d E,
$$

where $V^{*}$ is the total amount of volatiles from the pyrolysis reaction, $V$ is the volatile amount evolved by time $\mathrm{t}$, and $V / V^{*}$ is the conversion ratio at the corresponding time, $t$. $A$ is the pre-exponential factor, $E$ is the apparent activation energy, $\mathrm{R}$ is the universal gas constant, and $\mathrm{T}$ is the reaction temperature $(\mathrm{K}) . f(E)$ is the activation energy distribution function, which follows Equation (2):

$$
\int_{0}^{\infty} f(E) d E=1
$$

For non-isothermal conditions, Equation (2) can be modified under a constant heating rate, $\beta=d T / d t$, as in the following equation:

$$
\Phi(E, T)=\exp \left(-\frac{A}{\beta} \int_{0}^{T} \exp \left(-\frac{E}{R T}\right) d T\right)
$$

Integration and simplification of Equation (3) gives the following logarithmic expression of the equation:

$$
\Phi(E, T)=\exp \left(-\frac{A R T^{2}}{\beta E} \exp \left(-\frac{E}{R T}\right)\right) .
$$

According to the Miura [42] integration method, the ultimate Arrhenius equation can be modified by:

$$
\ln \left(\frac{\beta}{T^{2}}\right)=\ln \left(\frac{A R}{E}\right)-\ln \left[-\ln \left(1-\frac{V}{V^{*}}\right)\right]-\frac{E}{R T} .
$$

Thus, the kinetic parameters, $E$ and $A$, can be determined from the liner plot of $\ln \left(\beta / T^{2}\right)$ versus $1 / T$ at different heating rates for the entire conversion ranging from 0 to 1. 


\section{Conclusions}

This study involved the influence of two different iron-based catalysts $\left(\mathrm{Fe}\left(\mathrm{NO}_{3}\right)_{3}\right.$ and $\left.\mathrm{FeCl}_{3}\right)$ on the thermal behavior and product distribution of THF extract obtained from a lignite.

The TGA results showed that with the separate addition of 5 wt $\% \mathrm{Fe}\left(\mathrm{NO}_{3}\right)_{3}$ and $\mathrm{FeCl}_{3}$, the conversion of THF extract increased to $84.38 \%$ and $89.66 \%$ from $77.88 \%$, and the final temperature was lowered to 650 and $550{ }^{\circ} \mathrm{C}$ from $700{ }^{\circ} \mathrm{C}$ simultaneously. The increase of the mass loss mainly occurred in two stages: $200-350{ }^{\circ} \mathrm{C}$ and $350-500{ }^{\circ} \mathrm{C}$. In summary, $\mathrm{Fe}\left(\mathrm{NO}_{3}\right)_{3}$ and $\mathrm{FeCl}_{3}$ demonstrated the catalytic reactivity for the decomposition of THF extract in the thermal treatment process and $\mathrm{FeCl}_{3}$ exhibited a better catalytic reactivity than $\mathrm{Fe}\left(\mathrm{NO}_{3}\right)_{3}$.

For the separate addition of $\mathrm{Fe}\left(\mathrm{NO}_{3}\right)_{3}$ and $\mathrm{FeCl}_{3}$, the evolution of $\mathrm{CH}_{4}$ and $\mathrm{H}_{2}$ commenced at approximately $100{ }^{\circ} \mathrm{C}$, and more short-chain aliphatic hydrocarbons were produced at about $150{ }^{\circ} \mathrm{C}$. The generation peak of $\mathrm{H}_{2} \mathrm{O}$ at around $570^{\circ} \mathrm{C}$ was remarkably increased, simultaneously. The evolution of $\mathrm{CH}_{4}$ showed an analogous trend in this temperature range. The generation temperature of $\mathrm{CO}_{2}$ was lowered to $200{ }^{\circ} \mathrm{C}$ from $400{ }^{\circ} \mathrm{C}$ with the separate addition of catalyst. More aliphatic side chains connected to aromatic structures facilitated cracking at approximately $500^{\circ} \mathrm{C}$, leading to more aliphatic hydrocarbons and aromatics, including benzene, toluene, and xylene generation, in this temperature range. Moreover, the intensity of $\mathrm{H}_{2}$ was remarkably enlarged in $400-500^{\circ} \mathrm{C}$. The sole evolution peak of $\mathrm{CO}$ appeared at approximately $500^{\circ} \mathrm{C}$, which was ascribed to the degradation of tar-O structures. Thus, the evolution curves of $\mathrm{CO}$ with/without catalyst remained nearly unchanged in this temperature range.

Kinetics analysis using the DAEM method is suitable for the catalytic thermal treatment of THF extract. With the separate addition of $\mathrm{Fe}\left(\mathrm{NO}_{3}\right)_{3}$ and $\mathrm{FeCl}_{3}$, the average activation energy of $\mathrm{EX}$ dramatically decreased to 146.63 and $122.17 \mathrm{kJmol}^{-1}$ from $102.39 \mathrm{kJmol}{ }^{-1}$.

Supplementary Materials: The following are available online at http://www.mdpi.com/2073-4344/9/11/953/s1, Figure S1: TGA curves for EX-Fe(N) at different heating rates, Figure S2: TGA curves for EX-Fe(C) at different heating rates, Figure S3: Arrhenius plot of DAEM method for EX-Fe(N), Figure S4: Arrhenius plot of DAEM method for EX-Fe(C), Table S1: Typical components in THF extract detected by GCXGC-MS, Table S2: Variation of $E$ and $A$ obtained from DAEM method for different samples.

Author Contributions: Conceptualization, W.H.; Data curation, J.L., W.H.; Formal analysis, J.L., Q.Z. and L.L.; Funding acquisition, W.H.; Investigation, J.L., Q.Z. and L.L.; Methodology, J.L. and Q.Z.; Project administration, W.H.; Software, J.L.; Validation, Q.Z.; Writing-original draft, J.L.; Writing-review and editing, J.L.

Funding: This work was supported by Natural Science Foundation of China (Grants 21776195 and 21975173), International Science \& Technology Cooperation Program (Grant 2013DFG60060) and National Research and Development Program of China (Grants 2018YFB060403-03 and 2018YFB0604600-01-03)

Conflicts of Interest: The authors declare no conflict of interest.

\section{References}

1. Dudley, B. BP Statistical Review of World Energy; ISO 14001; Pureprint Group Limited: Uckfield, UK, 2018.

2. Lievens, C.; Ci, D.; Bai, Y.; Ma, L.; Zhang, R.; Chen, J.Y.; Gai, Q.; Long, Y.; Guo, X. A study of slow pyrolysis of one low rank coal via pyrolysis-GC/MS. Fuel Process. Technol. 2013, 116, 85-93. [CrossRef]

3. Li, G.; Yan, L.; Zhao, R.; Li, F. Improving aromatic hydrocarbons yield from coal pyrolysis volatile products over HZSM-5 and Mo-modified HZSM-5. Fuel 2014, 130, 154-159. [CrossRef]

4. Li, B.; Lv, W.; Zhang, Q.; Wang, T.; Ma, L. Pyrolysis and catalytic pyrolysis of industrial lignins by TG-FTIR: Kinetics and products. J. Anal. Appl. Pyrolysis 2014, 108, 295-300. [CrossRef]

5. Fu, Y.; Guo, Y.; Zhang, K. Influence of Three Different Catalysts $\left(\mathrm{KCl}, \mathrm{CaO}\right.$, and $\left.\mathrm{Fe}_{2} \mathrm{O}_{3}\right)$ on the Reactivity and Mechanism of Low-Rank Coal Pyrolysis. Energy Fuel 2016, 30, 2428-2433. [CrossRef]

6. Altuntas, N.; Yurum, Y. Influence of Catalysts on the Pyrolysis of Turkish Zonguldak Bituminous Coal. Energy Fuel 2000, 14, 820-827. [CrossRef]

7. Kang, S.G.; Zong, Z.M.; Shui, H.F.; Wang, Z.C.; Wei, X.Y. Comparison of catalytic hydroliquefaction of Xiaolongtan lignite over $\mathrm{FeS}, \mathrm{FeS}+\mathrm{S}$ and $\mathrm{SO}_{4}{ }^{2-} / \mathrm{ZrO}_{2}$. Energy 2011, 36, 41-45. [CrossRef] 
8. Monterroso, R.; Fan, M.; Zhang, F.; Gao, Y.; Popa, T.; Argyle, M.D.; Towler, B.; Sun, Q.Y. Influences of an environmentally-friendly, inexpensive composite iron-sodium catalyst on coal gasification. Fuel 2014, 116, 341-349. [CrossRef]

9. He, L.; Hui, H.L.; Li, S.G.; Lin, W.G. Production of light aromatic hydrocarbons by catalytic. Fuel 2018, 216, 227-232. [CrossRef]

10. Shi, Z.; Jin, L.; Zhou, Y.; Li, H.; Li, Y.; Hu, H. In-situ analysis of catalytic pyrolysis of Baiyinhua coal with pyrolysis time-of-flight mass spectrometry. Fuel 2018, 227, 386-393. [CrossRef]

11. Seitz, M.; Heschel, W.; Nagler, T.; Nowak, S.; Zimmermann, J.; Stam-Creutz, T.; Frank, W.; Appelt, J.; Bieling, S.; Meyer, B. Influence of catalysts on the pyrolysis of lignites. Fuel 2014, 134, 669-676. [CrossRef]

12. Sekiguchi, Y.; Klabunde, K.J. Catalytic and non-catalytic flow-pyrolysis of bibenzyl. Possible homolytic and heterolytic processes on basic CaO. Fuel Process. Technol. 1981, 4, 73-84. [CrossRef]

13. Wang, M.F.; Zuo, Z.J.; Ren, R.P.; Gao, Z.H.; Huang, W. Theoretical Study on Catalytic Pyrolysis of Benzoic Acid as a Coal-Based Model Compound. Energy Fuels 2016, 30, 2833-2840. [CrossRef]

14. Song, Q.; Cai, J.; Zhang, J.; Yu, W.; Wang, F.; Xu, J. Hydrogenation and cleavage of the C-O bonds in the lignin model compound phenethyl phenyl ether over a nickel-based catalyst. Chin. J. Catal. 2013, 34, 651-658. [CrossRef]

15. Pinto, I.G.; Lobo, L.S.; Cabrita, I. Effect of coal pre-treatment with swelling solvents on coal liquefaction. Fuel 1999, 78, 629-634. [CrossRef]

16. Zou, L.; Jin, L.; Li, Y.; Zhu, S.; Hu, H.Q. Influence of tetrahydrofuran extraction on lignite pyrolysis under nitrogen. J. Anal. Appl. Pyrolysis 2015, 112, 113-120. [CrossRef]

17. Takanohashi, T.Y.; Iino, M. Extraction and Swelling of Low-Rank Coals with Various Solvents at Room Temperature. Energy Fuel 1996, 10, 1128-1132. [CrossRef]

18. Qin, X.; Jiao, T.; Zhang, Y.; Yu, J.; Liang, P. Influence of solvent pretreatment on pyrolysis characteristic of high-sulfur bituminous coal. J. Anal. Appl. Pyrolysis 2018, 135, 54-59. [CrossRef]

19. Tran, Q.A.; Stanger, R.; Xie, W.; Smith, N.; Lucas, J.; Wall, T. Impacts of Mild Pyrolysis and Solvent Extraction on Coking Coal Thermoplasticity. Energy Fuel 2016, 30, 9293-9302. [CrossRef]

20. Iino, M.; Takanohashi, T.; Obara, S.; Tsueta, H.; Sanokawa, Y. Characterization of the extracts and residues from CS2-N-methyl-2-pyrrolidinone mixed solvent extraction. Fuel 1989, 68, 1588-1593. [CrossRef]

21. Zhao, Y.; Hu, H.; Jin, L.; He, X.F.; Wu, B. Pyrolysis behavior of vitrinite and inertinite from Chinese Pingshuo coal by TG-MS and in a fixed bed reactor. Fuel Process. Technol. 2011, 92, 780-786. [CrossRef]

22. Shi, D.L.; Wei, X.Y.; Fan, X.; Zong, Z.M.; Chen, B.; Zhao, Y.P.; Wang, Y.G.; Cao, J.P. Characterizations of the Extracts from Geting Bituminous Coal by Spectrometries. Energy Fuel 2013, 27, 3709-3717. [CrossRef]

23. Yamashita, H.; Yoshida, S.; Tomitat, A. Local Structures of Metals Dispersed on Coal. 1. Change of Local Structure of Iron Species on Brown Coal during Heat Treatment. Energy Fuel 1989, 3, 686-692. [CrossRef]

24. Yamashita, H.; Tomita, A. Local Structures of Metals Dispersed on Coal. 5. Influence of Coal, Catalyst Precursor, and Catalyst Preparation Method on the Structure of Iron Species during Heat Treatment and Steam Gasification. Ind. Eng. Chem. Res. 1993, 32, 409-415. [CrossRef]

25. Zhao, H.; Li, Y.; Song, Q.; Lv, J.; Shu, Y.; Liang, X.; Shu, X. Influences of Iron Ores on the Pyrolysis Characteristics of a Low-Rank Bituminous Coal. Energy Fuel 2016, 30, 3831-3839. [CrossRef]

26. Cyores, R.; Soudan-Moinet, C. Pyrolysis of coal and iron oxides mixtures.1. Influence of iron oxides on the pyrolysis of coal. Fuel 1980, 59, 48-54.

27. Boudou, J.B.; Alain, E.; Furdi, G.; Mareche, J.F.; Albiniak, A. Influences of $\mathrm{FeCl}_{3}$ (intercalated or not in graphite) on the pyrolysis of coal or coal tar pitch. Fuel 1998, 77, 601-606. [CrossRef]

28. Shi, L.; Liu, Q.; Guo, X.; Wu, W.; Liu, Z. Pyrolysis behavior and bonding information of coal—A TGA study. Fuel Process. Technol. 2013, 108, 125-132. [CrossRef]

29. Zhao, Y.; Liu, J.T.; Liang, W.S.; Huang, W.; Zuo, Z.J. Influence of the valence state change of iron oxidation for pyrolysis by using density functional theory. Appl. Surf. Sic. 1993, 32, 409-415. [CrossRef]

30. Liu, J.; Jiang, X.; Shen, J.; Zhang, H. Pyrolysis of superfine pulverized coal. Part 1. Mechanisms of methane formation. Energy Convers. Manag. 2014, 87, 1027-1038. [CrossRef]

31. Wang, M.; Li, Z.; Huang, W.; Yang, J.; Xue, H. Coal pyrolysis characteristics by TG-MS and its late gas generation potential. Fuel 2015, 156, 243-253. [CrossRef]

32. Liu, J.; Jiang, X.; Shen, J.; Zhang, H. Pyrolysis of superfine pulverized coal. Part 2. Mechanisms of carbon monoxide formation. Energy Convers. Manag. 2014, 87, 1039-1049. [CrossRef] 
33. Arenillas, A.; Rubiera, F.; Pis, J.; Cuesta, M.; Iglesias, M.; Jimenez, A.; Suarez-Ruiz, I. Thermal behaviour during the pyrolysis of low rank perhydrous coals. J. Anal. Appl. Pyrolysis 2003, 68-69, 371-385. [CrossRef]

34. Szabo, G.V.; Till, F.; Szekely, T. Investigation of subbituminous coals by thermogravimetry-mass spectrometry Part 1. formation of hydrocarbon products. Thermochim. Acta 1990, 170, 167-177. [CrossRef]

35. Yan, L.; Bai, Y.; Zhao, R.; Li, F.; Xie, K. Correlation between coal structure and release of the two organic compounds during pyrolysis. Fuel 2015, 145, 12-17. [CrossRef]

36. Tian, B.; Qiao, Y.; Bai, L.; Feng, W.; Jiang, Y.; Tian, Y. Pyrolysis behavior and kinetics of the trapped small molecular phase in a lignite. Energy Convers. Manag. 2017, 140, 109-120. [CrossRef]

37. Kawni, K.; Bhattacharya, S. Pyrolysis kinetics and reactivity of algae-coal blends. Biomass Bioenergy 2013, 55, 291-298.

38. Westhuizen, A.C.; Crouch, A.; Sandra, P. The use of GC $\times$ GC with time-of-flight mass spectrometry to investigate dienes and Diels-Alder polymerisation products in high-temperature Fischer-Tropsch-based fuels. J. Sep. Sci. 2008, 31, 3423-3428. [CrossRef]

39. Pierce, K.M.; Hoggard, J.C.; Mohler, R.E.; Synovec, R.E. Recent advancements in comprehensive two-dimensional separations with chemometrics. J. Chromatogr. A 2008, 1184, 341-352. [CrossRef]

40. Liu, J.; Zhang, Q.; Liang, L.; Guan, G.; Huang, W. Catalytic depolymerization of coal char over iron-based catalyst: Potential method for producing high value-added chemicals. Fuel 2017, 210, 329-333. [CrossRef]

41. Zhang, C.; Jiang, X.; Wei, L.; Wang, H. Research on pyrolysis characteristics and kinetics of super fine and conventional pulverized coal. Energy Convers. Manag. 2007, 48, 797-802. [CrossRef]

42. Miura, K.; Maki, T. A simple method for estimating $\mathrm{f}(\mathrm{E})$ and $\mathrm{K}_{0}(\mathrm{E})$ in the distributed activation energy model. Energy Fuel 1998, 12, 864-869. [CrossRef]

(C) 2019 by the authors. Licensee MDPI, Basel, Switzerland. This article is an open access article distributed under the terms and conditions of the Creative Commons Attribution (CC BY) license (http://creativecommons.org/licenses/by/4.0/). 